\title{
SCREENING OF TOXOPLASMA GONDII INFECTION AMONG CHILDBEAR- ING AGE FEMALES AND ASSESSMENT OF NURSES' ROLE IN PREVENTION AND CONTROL OF TOXOPLASMOSIS By
}

\author{
AHMED MEGAHED AHMED SALEH ${ }^{1}$, HISHAM ABD EL-RAOUF ALI' ${ }^{2}$ SALWA \\ ABDALLA MOHAMED AHMED ${ }^{3}$, SAMAH MOSTAFA HOSNY ${ }^{4}$ \\ AND TOSSON A. MORSY
}

Military Institute of Health and Epidemiology ${ }^{1,3,4}$ and Medical Surgical Nursing ${ }^{3}$, The Military Medical Academy ${ }^{1,2,3,4}$ and Department of Parasitology, Faculty of Medicine, Ain Shams University, Cairo $11566^{5}$, Egypt

\begin{abstract}
Toxoplasmosis, caused by Toxoplasma gondii is an obligate intracellular zoonotic protozoan parasite, with a worldwide distribution particularly in Arab countries including Egypt. The study evaluated toxoplasmosis infection among childbearing age Egyptian females and assessed the military nursing staff knowledge, attitude and compliance to toxoplasmosis prevention and control measures. The study was conducted in a general military hospital.

Research design: cross-section descriptive research design was used to conduct this study. The subjects consisted of 14 young females (11 were in-patients undergoing gynecological treatment in a military hospital and 3 were staff nurses. On the other hand, 44 staff nurses were available for assessment who met the inclusion criteria

Tools: 4 tools were used for data collection: first consisted of self-administered questionnaires to assess nurses' socio-demographic data and knowledge, second rating scale to assess nurses' attitude towards toxoplasmosis infection and its prevention, third performance check list to measure nurses' compliance to infection control measures, and fourth measured the antiToxoplasma antibodies by commercial indirect hemagglutination test (IHAT).

The results showed that almost half of the nurses had satisfactory levels of knowledge, attitude, and compliance to toxoplasmosis infection control measures. $22.2 \%$ of the pregnant women and $20 \%$ of non-pregnant ones showed antibodies against $T$. gondii.

Thus health education about toxoplasmosis should be tailored to women whether married or single to help in avoiding the risk of infection. Frequent periodic IHAT should be done for people who continuously contact with cats. Adherence to strict infection prevention measures is a must to eliminate exposure to toxoplasmosis infection. Training intervention should be implemented to achieve successful improvement in knowledge, attitude, and compliance of toxoplasmosis control measures.
\end{abstract}

Key words: Toxoplasmosis, knowledge, Attitude, Compliance, Nursing Staff, Military Hospital

\section{Introduction}

The Apicomplexan Toxoplasma gondii, the causative agent of toxoplasmosis, is a very successful parasite that can infect virtually all warm blooded animals causes a large range of clinical manifestations up to death with marked biological differences exist among strains in the pathogenicity and geographical distribution (Su et al, 2012). While human infection can occur via ingestion of tissue cysts from infected meat, most human infection comes from oocysts. Cats are the only definitive host, and thus shedding of oocysts by cats provides the ultimate source of toxoplasmosis. So, felines serve as definitive hosts, while all other vertebrates, including man act as intermediate hosts of the parasite with disseminated tissue infections (Lilly and Wortham, 2013). The parasite is distributed worldwide in the human population and is estimated to affect more than a billion individuals. The parasite has significant impact not only on animal production but also on public health throughout the world (Sudan et al, 2013). Up to one third of the world's population was estimated to car- 
ry Toxoplasma infection (Jones and Roberts, 2012).Toxoplasmosis is considered to be a leading cause of death attributed to food borne illness in the United States. More than 60 million men, women, and children in the U.S. carry the Toxoplasma parasite, but very few have symptoms because the immune system usually keeps the parasite from causing illness (Pappas et al, 2009).

Abroad, toxoplasmosis ranged from 7.595\% worldwide: $7.5 \%$ in Scotland (Jackson and Hutchinson, 1987), 22.5 up to $37.4 \%$ in Saudi Arabia (Shoura et al, 1973; Abbas et al, 1986), 50\% in USA (Stagno, 1980), $54.0 \%$ in Kenya (Griffin and Williams, 1983), 37.5\% in Libya (Kassem and Morsy, 1991), 47\% in Nigeria (Onadeko et al., 1992), 37\% in Jordan (Morsy and Michael, 1980), and 95.5\% in Kuwait (Behbehani and Al-Karmi, 1980). Alonso et al. (1984) stated that patients with AIDS developed up to $50 \%$ cerebral toxoplasmosis.

In Egypt, $T$. gondii and toxoplasmosis is a well-documented zoonotic disease in man (Elsheikha and Morsy, 2009), particularly infants and children (Wishahy et al, 1973) and women (Eissa et al, 1990) and edible animals (Rifaat et al, 1977), camels (Hilali et al, 1998), and rabbits (Harfoush and Tahoon, 2010) as well as equines (Haridy et al, 2009), donkeys' milk (Haridy et al, 2010), birds (Rifaat et al, 1969) and pet and stray animals (Khalid et al, 1982), stray dogs (El Behairy et al, 2013) as well as domestic and wild rodents (Morsy et al, 1987). Besides, $T$. gondii antibodies were reported in Egyptian blood donors associated risk factors for the blood transmission (Elsheikha et al, 2009).

Al-Kappany et al. (2010) in Egypt isolated 115 viable $T$. gondii isolates from cats' tissues and genotyped by 10 PCR-restriction fragment length polymorphism markers (SAG1, SAG2, SAG3, BTUB, GRA6, c228, c29-2, L358, PK1, and Apico) and DNA from tachyzoites. They concluded that a strong clonal population structure with the dominance of clonal Type II and III lineages of $T$. gondii in feral cats from Egypt. Al-
Kappany et al. (2011) demonstrated a high prevalence of $T$. gondii, Bartonella spp., and FIV infections in cats from Cairo. They added that cats are important in the epidemiology of $T$. gondii because they are the only hosts that excrete environmentally resistant oocysts in feces. In the definitive host or cats, the bradyzoite replicates slowly, exhibits low immunogenicity, and partly protects the host from parasite-induced cell rupture and immunopathology (Costa et al, 2012).

To prevent food-borne horizontal transmission of $T$. gondii to humans, all meat should be well cooked to a minimum temperature of $67^{\circ} \mathrm{C}$ before consuming so as to kill tissue cysts. Tissue cysts can also be killed by cooling to $-13^{\circ} \mathrm{C}$. Pregnant women should be especially careful, and should limit contact with cats, cat litter, soil and raw meat (Hill and Dubey, 2002). Abdulmawjood et al. (2014) investigated the persistence of $T$. gondii in raw sausages using in-house developed and validated real timePCR, reported that $T$. gondii survived in relation to the raw-sausage-manufacturingprocess including the different ripening processes.

Bazaco et al. (2008) stated that one of the duties the nurse is to offer well cooked meat and well washed green salad to the pregnant women to prevent them from acquiring toxoplasmosis and to delivery infants with congenital infection. Ziemba et al. (2010) assessed knowledge of toxoplasmosis among obstetricians, medical students, midwifes and pregnant women, as follows: 1) evaluation of intra- and inter-group variation in correct answers to the questions included in the questionnaire used as a study tool; 2) evaluation of inter-group variation in answers to specialist and non-specialist questions; and 3) intra-group evaluation of selfassessed difficulty in completing the questionnaire. They found that pregnant women assessed their knowledge of toxoplasmosis as least adequate, whereas midwifes, as most adequate. The pregnant women's knowledge about toxoplasmosis is poor. The group of 
physicians and medical students yielded evidently better score than pregnant women. They concluded that there was a need for the improvement among prenatal care providers in both patient education and self-education.

\section{Subjects, Materials and Methods}

The aim of the study was to detect Toxoplasma gondii infection among childbearing age Egyptian females $(n=14)$ and to assess the military nursing staff $(n=40)$ measures related to toxoplasmosis prevention as a zoonotic disease, and suggest recommendations to improve their quality of care related to this infectious disease. The childbearing age females were subjected to a complete history taking using a structural questionnaire with special emphasis on risk factors to toxoplasmosis. Clinical examination was carried out for signs and symptoms suggestive of toxoplasmosis such as miscarriage, fever, enlarged lymph nodes, hepatosplenomegaly, and/or skin rash.

Objectives: 1-To detect toxoplasmosis positive infection among young Egyptian females. 2- To assess nurses' knowledge as regards the risk of toxoplasmosis as a congenital and acquired disease at a military hospital. 3- To assess the nurses' attitude toward the toxoplasmosis prevention. 4- To assess nurses' compliance to toxoplasmosis infection control measures. 5- To suggest feasible recommendations to improve nurses' performance when dealing with toxoplasmosis patient.

Research design: A cross-section descriptive study was used in carrying out this study to detect positive patients of toxoplasmosis infection and evaluate nurses' knowledge, attitude and compliance to infection control measures.

Study setting: The study was conducted in General Military Hospital. A total of 14 young females were randomly selected within age group of (30-40 years old), of whom nine were pregnant and five were not pregnant. A total of 44 staff nurses, the whole number of nurses available in the hospital, 4 of them were excluded because of the pilot study and 40 were able to complete all data collection procedure. Four tools were used for data collection

First tool: Consisted of self- administered questionnaires, consists of two parts: the first part concerned with subjects' sociodemographic data related to age, sex, marital status qualifications, years of working experience and attendance of previous training program on Toxoplasmosis. While the second part dealt with assessment of nurses' knowledge related to toxoplasmosis. Nurses' knowledge was evaluated through (42) different questions: Epidemiology (7 items), Symptoms (12 items), Complications (9 items), Diagnosis (5 items) and Prevention (9 items). Scoring system: Each question was evaluated through giving score of " 1 "for each correct answer, and zero for each wrong answer. These scores were converted into a percent score. Knowledge was considered correct or satisfactory if the percent score was $60 \%$ or more and unsatisfactory if less than $60 \%$.

Second tool: Rating scale contains 25 items to assess nurses' attitude towards toxoplasmosis infection and its prevention such as importance of infection control measures, precautions for cooking meat, precautions for cat raising, training program, health education, importance of prevention, vaccination, quarantine measures and dealing with suspected cases Scoring system: For the positive attitude rating scale, the response of agree was given (1) while not sure or disagree was given (zero).

Third tool: Performance check list to measure nurses' compliance to toxoplasmosis infection control measures such as precautions for BBPs prevention, hand washing, periodic medical examination, toxoplasmosis investigations, notification of infection and hospital waste management.

Fourth tool: Testing anti-Toxoplasma antibodies by indirect hemagglutination test using commercial Toxo-IHA Fumouze, Diagnostics, France), Sera were collected aseptically from 14 females, nine of them were 
pregnant of who six were inpatients and three were staff nurses in the military hospital.

Validity Test: the developed questionnaires were submitted to a panel of three experts in the field of nursing education, infection control and epidemiology for ensuring relevancy, clarity, and readability, ease of understanding, question sequence, and completion time. Then, questionnaires\& checklist were edited according to experts' suggestions.

Reliability Test: Reliability test was done by using the internal consistency reliability test (Cronbach's alpha). The reliability coefficients were generally high for all questionnaires, and suitable for scientific purposes. The reliability coefficients for each questionnaire were: 1- Knowledge test: 0.86, 2Nurses' attitude towards toxoplasmosis infection and prevention: 0.80 , and 3- Observational checklist: 0.82

Data collection procedure: A formal letter from the hospital manager was taken to get his permission to collect data before distributing the questionnaire. The researcher explained to the subjects included in the study the purposes, benefits, and ethical considerations of this study. Actual fieldwork started at the beginning of July /2013 to the end October / of 2013.

Statistical analysis (Data management): The collected data were presented by tables, computerized and statistically analyzed using Statistical Package of Social Services version 20 (SPSS). Data was presented using descriptive statistics in the form of frequencies and percentages for qualitative variables, and means, and standard deviations for quantitative variables. Quantitative continuous data was analyzed using Student ttest. Qualitative categorical variables were compared using chi-square or Fisher exact tests as suitable. Test results were considered significant when $\mathrm{p}$-value $<0.05$, and $\mathrm{p}$ value $<0.01 \&<0.001$ were considered highly significant.

\section{Results}

A total of 14 females were examined for anti-toxoplasma antibodies by IHAT. Of the nine pregnant females seven were negative; one gave reaction at dilution 1:32 and one at dilution 1:128 with a total positivity of $22.2 \%$. Of the five non-pregnant females four were negative and one gave positive reaction at dilution 1:64 (Tab. 1).

Half of the nurses $(50.0 \%)$ were in the age category 20-30 years, of who $75.0 \%$ were females, and $55.0 \%$ were single (Tab. 2).

A total of $52.5 \%$ of the participant nurses had nursing school diploma, and $65.0 \%$ of them were Sub-officer. More than half of participants $(52.5 \%)$ had 5-10 years' work experience. The work experience of the participants ranged from (2.0 to 20.0years) and the mean was $8.43+4.87$ years. On the other hand, $40.0 \%$ were working in medical departments, while $35.0 \%$ were working in surgical ones and $25.0 \%$ were from the high pressure areas as emergency \& ICU departments (Tab. 3).

Almost half of participant nurses (55\%) had satisfactory knowledge level as regards toxoplasmosis without significant difference ( $\mathrm{P}>0.05$ ). between all topics (Tab. 4).

A total of $50 \%$ of the nurses had positive attitude towards toxoplasmosis infection and prevention without significant $(\mathrm{P}>0.05)$ difference between all topics (Tab. 5).

A total of $60 \%$ of them had achieved positive compliance to infection control measures with significant higher score $(\mathrm{P}<0.05)$ for precautions for BBPs prevention (Tab. 6).

There was a statistically significant difference between the total mean knowledge \% score according to sex, education, and marital status $(\mathrm{P}>0.05)$. Also, there was a significant difference between the total mean attitude \% score according to sex, education, and marital status $(\mathrm{P}<0.05)$. However, there was a significant difference between the total mean compliance \% score according to education and years of experience (Tab. 7). 
Table 1: Anti-Toxoplasma gondii antibodies by Indirect Hemagglutination Test (IHAT)

\begin{tabular}{|c|c|c|c|c|c|c|}
\hline Subject & \multirow{2}{*}{ No. } & \multicolumn{4}{|c|}{ IHAT } & \multirow{2}{*}{$+\mathrm{ve} \%$} \\
\cline { 3 - 6 } & & $-\mathrm{ve}$ & $1: 32$ & $1: 64$ & $1: 128$ & \\
\hline Pregnant & 9 & 7 & 1 & -- & 1 & 22.2 \\
\hline Not pregnant & 5 & 4 & -- & 1 & -- & 20 \\
\hline Total & 14 & 11 & 1 & 1 & 1 & 21.4 \\
\hline
\end{tabular}

Table2: Frequency distribution of nursing staff as regards personal data (age, sex, and marital status)

\begin{tabular}{|c|c|c|c|c|c|}
\hline Age & No. & $\%$ & Total & $\chi^{2}$ test & $\mathrm{P}$ value \\
\hline$<20$ years & 8 & 20.0 & \multirow{3}{*}{40} & \multirow{3}{*}{8.4} & \multirow{3}{*}{$0.015^{*}$} \\
\hline $20-<30$ years & 20 & 50.0 & & & \\
\hline $30+$ years & 12 & 30.0 & & & \\
\hline \multirow{2}{*}{ Descriptive Statistics } & \multicolumn{2}{|c|}{ Mean \pm SD } & \multicolumn{3}{|c|}{ Range } \\
\hline & \multicolumn{2}{|c|}{$26.33+6.79$} & \multicolumn{3}{|c|}{$(19.0-43.0)$} \\
\hline Sex & No. & $\%$ & Total & $\chi^{2}$ test & $\mathrm{P}$ value \\
\hline Male & 10 & 25.0 & \multirow{2}{*}{40} & \multirow{2}{*}{20.0} & \multirow{2}{*}{$0.000 * *$} \\
\hline Female & 30 & 75.0 & & & \\
\hline Marital Status & No. & $\%$ & Total & $\chi^{2}$ test & $\mathrm{P}$ value \\
\hline Single & 15 & 37.5 & \multirow{3}{*}{40} & \multirow{3}{*}{20.8} & \multirow{3}{*}{$0.000 * *$} \\
\hline Married & 22 & 55.0 & & & \\
\hline Divorced/Widow & 3 & 7.5 & & & \\
\hline
\end{tabular}

*Statistically significant at $\mathrm{p}<0.05, * *$ Highly significant at $\mathrm{p}<0.01$

Table 3: Frequency distribution of nursing staff as regards professional data (educational level, years of experience, and work department)

\begin{tabular}{|c|c|c|c|c|c|}
\hline Education level & No. & $\%$ & Total & $\chi^{2}$ test & $\mathrm{P}$ value \\
\hline Bachelor degree & 10 & 25.0 & \multirow{3}{*}{40} & \multirow{3}{*}{9.98} & \multirow{3}{*}{$0.005 * *$} \\
\hline Technical Institute of Nursing & 9 & 22.5 & & & \\
\hline Diploma & 21 & 52.5 & & & \\
\hline Rank & No. & $\%$ & Total & $\chi^{2}$ test & $\mathrm{P}$ value \\
\hline Officer & 14 & 35.0 & \multirow{2}{*}{40} & \multirow{2}{*}{7.2} & \multirow{2}{*}{$0.007 * *$} \\
\hline Sub-officer & 26 & 65.0 & & & \\
\hline Years of experience & No. & $\%$ & Total & $\chi^{2}$ test & $\mathrm{P}$ value \\
\hline$<5$ years & 10 & 25.0 & \multirow{3}{*}{40} & \multirow{3}{*}{9.97} & \multirow{3}{*}{$0.006^{* *}$} \\
\hline $5-<10$ years & 21 & 52.5 & & & \\
\hline $10+$ years & 9 & 22.5 & & & \\
\hline \multirow{2}{*}{ Descriptive Statistics } & \multicolumn{2}{|c|}{ Mean + SD } & \multirow{2}{*}{\multicolumn{3}{|c|}{\begin{tabular}{|l|} 
Range \\
$(2.00-20.00)$ \\
\end{tabular}}} \\
\hline & \multicolumn{2}{|c|}{$8.43+4.87$} & & & \\
\hline Department & No. & $\%$ & Total & $\chi^{2}$ test & $\mathrm{P}$ value \\
\hline Medical & 16 & 40.0 & \multirow{3}{*}{40} & \multirow{3}{*}{2.10} & \multirow{3}{*}{0.350} \\
\hline Surgical & 14 & 35.0 & & & \\
\hline Emergency/ICU (High Pressure Areas) & 10 & 25.0 & & & \\
\hline
\end{tabular}

Table 4: Satisfactory knowledge level (score $60 \%,+$ ) of nurses as regards toxoplasmosis

\begin{tabular}{|c|c|c|c|c|}
\hline Topics & No. & $\%$ & $\chi^{2}$ test & $P$ value \\
\hline Epidemiology & 18 & 45.0 & \multirow{6}{*}{3.52} & \multirow{6}{*}{0.475} \\
\hline Symptoms & 20 & 50.0 & & \\
\hline Complications & 24 & 60.0 & & \\
\hline Diagnosis & 16 & 40.0 & & \\
\hline Prevention & 20 & 50.0 & & \\
\hline Total & 22 & 55.0 & & \\
\hline
\end{tabular}


Table 5: Nurses' attitudes $(\mathrm{N}=40)$ towards toxoplasmosis infection and its prevention

\begin{tabular}{|c|c|c|c|c|c|c|}
\hline \multirow{2}{*}{ Topics } & \multicolumn{2}{|c|}{ +ve attitude } & \multicolumn{2}{|c|}{-ve attitude } & \multirow[b]{2}{*}{$X^{2}$} & \multirow[b]{2}{*}{$\mathrm{p}$ value } \\
\hline & No. & $\%$ & No. & $\%$ & & \\
\hline Dealing with suspected cases & 17 & 42.5 & 23 & 57.5 & \multirow{11}{*}{4.77} & \multirow{11}{*}{0.265} \\
\hline Quarantine measures for defined cases & 21 & 52.5 & 19 & 47.5 & & \\
\hline Investigations for at risk & 17 & 42.5 & 23 & 57.5 & & \\
\hline Vaccinations for communicable diseases & 22 & 55.0 & 18 & 45.0 & & \\
\hline Importance of prevention & 21 & 52.5 & 19 & 47.5 & & \\
\hline Toxoplasmosis health education & 19 & 47.5 & 21 & 52.5 & & \\
\hline Toxoplasmosis training programs & 22 & 55.0 & 18 & 45.0 & & \\
\hline Precautions for cat raising & 21 & 52.5 & 19 & 47.5 & & \\
\hline Precautions for cooking meat & 19 & 47.5 & 21 & 52.5 & & \\
\hline Importance of infection control measures & 18 & 45.0 & 22 & 55.0 & & \\
\hline Total & 20 & 50.0 & 20 & 50.0 & & \\
\hline
\end{tabular}

Table 6: Nurses' compliance scale $(\mathrm{N}=40)$ to $T$. gondii infection control measures

\begin{tabular}{|l|l|l|l|l|l|l|}
\hline \multirow{2}{*}{ Measures Items } & \multicolumn{2}{|l|}{ +ve compliance } & \multicolumn{2}{|c|}{-ve compliance } & \multirow{2}{*}{ p value } \\
\cline { 2 - 5 } & No. & $\%$ & No. & $\%$ & \multirow{2}{*}{$\mathrm{X}^{2}$} & \\
\hline Application of Infection control measures & 24 & 60.0 & 16 & 40.0 & & \\
\hline Training for toxoplasmosis prevention & 23 & 57.5 & 17 & 42.5 & & \\
\hline Precautions for BBPs prevention & 26 & 65.0 & 14 & 35.0 & & \\
\hline Hand washing measures & 20 & 50.0 & 20 & 50.0 & & \\
\hline Periodic medical examination & 22 & 55.0 & 18 & 45.0 & & \\
\hline Toxoplasmosis Investigations & 25 & 62.5 & 15 & 37.5 & & \\
\hline Notification for toxoplasmosis infections & 18 & 45.0 & 22 & 55.0 & \multirow{3}{*}{3.93} & \multirow{2}{*}{$0.031^{*}$} \\
\hline Hospital Waste management & 22 & 55.0 & 18 & 45.0 & \\
\hline Total & 24 & 60.0 & 16 & 40.0 & & \\
\hline
\end{tabular}

Table 7: Relationship between subjects' sociodemographic data and total knowledge, attitude and compliance percent score

\begin{tabular}{|l|c|c|c|c|c|c|}
\hline Items & Sex & Age & Marital Status & Education & $\begin{array}{c}\text { Years of } \\
\text { experience }\end{array}$ & $\begin{array}{c}\text { Working } \\
\text { department }\end{array}$ \\
\hline Knowledge: & 1.892 & 0.319 & 2.144 & 3.173 & 1.918 & 1.632 \\
\hline P & $0.03^{*}$ & 0.728 & $0.038^{*}$ & $0.049^{*}$ & 0.156 & 0.237 \\
\hline Attitude & 1.875 & 0.632 & 2.144 & 1.984 & 0.887 & 0.945 \\
\hline P & $0.048^{*}$ & 0.657 & $0.042^{*}$ & $0.037^{*}$ & 0.213 & 0.167 \\
\hline Compliance & 0.983 & 0.632 & 2.144 & 1.984 & 0.887 & 0.945 \\
\hline P & 0.872 & 0.657 & 0.287 & $0.043^{*}$ & $0.023^{*}$ & 0.167 \\
\hline
\end{tabular}

\section{Discussion}

Toxoplasmosis, a zoonosis caused by obligate intracellular protozoan. The prevalence of toxoplasmosis varies greatly around the world. Prevalence rates are thought to depend on food production and harvesting practices, water treatment, environment, climate, and exposure to soil or sand. In immune-competent individuals, the infection usually is benign and self-limited. Severe forms are secondary to infection in immunocompromised patients or when acquired during pregnancy, when it may cause congenital disease with severe visual and neurological impairment. It is important that nurses be aware of this disease, recognize when it should be considered as a differential diagnosis, and understand how it is diagnosed and treated (Jones et al, 2007).

As the parasite can cross the placenta, toxoplasma infection may lead to the spontaneous abortion, stillbirth, neonatal death, premature labor or the congenital anomalies (Chaudhry et al, 2014). Wallon et al. (2013) stated that Toxoplasma infection during pregnancy exposes the fetus to risks of con- 
genital infection and sequelae that depend heavily on gestational age (GA) at time of infection. Accurate risk estimates by GA are necessary to counsel parents and improve clinical decisions. They concluded that introduction of monthly prenatal screening and improvement in antenatal diagnosis were associated with a significant reduction in the rate of congenital infection and a better outcome at 3 years of age in infected children

In the present study 14 females were examined for anti-Toxoplasma antibodies. Of the nine pregnant females seven were negative with a total positivity of $22.2 \%$. Of the five non-pregnant females four were negative and one gave positive reaction (20\%). The positive single staff nurse had pet cat since she was a university student.

It is critical in pregnant women to determine as exactly as possible if they acquired the infection just prior to or during gestation. No doubt, the presence of specific $\mathrm{IgG}$ antibodies rising titer and/or specific IgM antibodies are the best indicator of active infection (Barsoum,2006), but this diagnosis strategy may need to have more than one sample from the patient. Moncada and Montoya (2012) stated that more than a third of the world's population has been infected with the parasite, but seroprevalence is unevenly distributed across countries and different socioeconomic strata Congenital toxoplasmosis can be prevented and treated during gestation. Less severe disease is commonly reported in countries where prenatal screening and treatment have been systematically implemented. By contrast, severe disease appears to be observed primarily in infants born to untreated mothers Mumcuoglu et al. (2014) concluded that a diagnostic algorithm related to toxoplasmosis serology should be implemented for the appropriate evaluation of the risk of acute toxoplasmosis during pregnancy. Such an approach is necessary to support the clinical diagnosis and to minimize the anxiety in pregnant women about congenital toxoplasmosis. When toxoplasmic infection is acquired for the first time during pregnancy, infection can be transmitted to the fetus, resulting in congenital toxoplasmosis and associated neurological and ocular manifestations (Paquet and Yudin, 2013).

On the other hand, Amin et al. (2013) reported that many cases of congenital toxoplasmosis could be prevented provided that the pregnant women following hygienic measures to avert risk of infection and to reduce severity of the condition if primary prevention failed. They added that Saudi Arabian pregnant women were substantially vulnerable to toxoplasmosis infection as they are lacking the necessary preventive behavior. A sizable portion have no sufficient knowledge for primary prevention of congenital toxoplasmosis, health education at primary care is necessary to avert the potential toxoplasmosis related complications especially in the neonates.

The current study included 40 military nursing staff, as regards socio-demographic characteristics of the participants results revealed that half of the participants were lying in the age category 20 -30years $(50.0 \%)$; In addition there is a statistically significant difference between participants as regard their age categories $(\mathrm{P}<0.05)$. Regarding the nursing Staff by gender the majority of the participants about (75.0\%) were females; with a highly statistically significant difference $(\mathrm{P}<0.01)$. This result agreed with Mutale et al. (2013a) who accounted men in nursing as equal to $6.6 \%$. They added that variation in motivation score by sex, type of health worker, training and time in post. Further research is needed to establish why these health worker attributes were associated with motivation and whether health system interventions targeting health workers, such as the current intervention, could influence health worker motivation. Also, Mutale et al. (2013b) stated that health worker motivation can potentially affect the provision of health services. They found that it was feasible to 
measure governance practices at health facility level and that the adapted tool is fairly reliable with $95 \%$ one-sided confidence interval for Cronbach's alpha laying between 0.69 and 0.74 for the 16 items, and that caution should be taken when interpreting overall scores as they tended to mask domain specific variations.

In the present study, $55.0 \%$ of participants were single with a highly significant difference as regards marital status $(\mathrm{P}<0.01)$. Yang et al. (2008) in China, mentioned that the hospital managers should think highly of sleep quality of ward nurses, acknowledge its degree of work fatigue and apply evidence based methods arrange work responsibility and follow sheet, then rationalize human resources management, emphasize sleep hygiene education, improve sleep quality and reduce work fatigue and consequently have time for her family life. Liou and Cheng (2010) reported that creating a good organisational climate might increase nurses' organisational commitment and, in turn, decrease their intention to leave.

On the other hand, Tabi et al. (2010) in USA stated that the polygyny or the practice of taking more than one wife at the same time is a common practice in several countries including Africa. They concluded that these findings have implications for nursing and policy-makers who should be aware of the implications of polygynous marriages on women's health and well-being. El-Jardali et al. (2013) stated that the Lebanese nursing workforce shortages in difficult-to-staff areas have implications not only for quality of care but also for population health outcomes. They found that marriage was positively associated with intent to stay in Lebanon and Jordan whereas years of experience were positively significant for Lebanon and Yemen.

In the present study, almost half of the participant nurses $(55.0 \%)$ had satisfactory knowledge level as regards toxoplasmosis without significant difference between all topics $(\mathrm{P}>0.05)$. The result agreed with the cross-sectional study of Silva et al. (2001) on (118) physicians and nurses who provide prenatal care at public health units of a midsize Brazilian city; where only $44.4 \%$ of participant nurses had the satisfactory knowledge level. Also, the basic knowledge of nurses in issues related to prevention is inconsistent with the role of nurses as health educators. In contrast Khudair and Raza (2013) on (70) nurses who provide prenatal care to pregnant women at primary health care centers in Qatar; where $(44.3 \%)$ of nurses have moderate level of knowledge and about one third of them $(35.7 \%)$ were with good. The nurses who work in prenatal care units have a wide work area. Therefore, it is necessary those nurses have a general education as the proper conduct of health problems.

Attitude is defined as a psychological tendency. Bampi et al. (2013) evaluated nurse undergraduate students' perception of quality of life. They found that the psychological and environment domains were assessed as the best and worst scores, respectively. The facets called Thinking, learning, memory and concentration, sleep and rest energy and fatigue, activities of daily living, work capacity, participation in and opportunities for the recreation/leisure activities, financial resources and negative feelings were affected. The facets with the worst score influenced negatively the quality of life for students and might trigger negative feelings such as bad mood, desperation anxiety and depression. Abeni et al. (2014) reported that here was much evidence demonstrating that psychosocial interventions in caregivers and oncological staff produce an improvement in their patients' quality of life. They added that group treatment focused on changing personal responses to stressful situations can induce more adaptive strategies enabling caregivers, hematologists, and nurses to help patients better and thereby improve their quality of life. So, evaluation of attitude towards certain topic can help to know the readiness of the target people to know what 
is new in that topic. Freimann et al. (2013) described the prevalence of musculoskeletal pain (MSP) amongst Estonian nurses, and to explore associations with personal characteristics and occupational risk factors. The prevalence of musculoskeletal pain (MSP) among Estonian nurses is high. Psychological risk factors such as somatising tendency have an important impact. However, none of the risk factors examined seems likely to explain the high frequency of work-related musculoskeletal disorders in Estonia. They concluded that the prevalence of MSP among Estonian nurses was high and that psychological risk factors such as somatising tendency had an important impact. Segal et al. (2014) assessed the efficacy and safety of glycaemic control by a nurse-guided protocol with physician-guided therapy and assessed the impact of empowerment on the nurses' sense of competence. They concluded that an empowerment questionnaire showed tendency for increased nurses' sense of competence. Nurse-guided protocol was non-inferior to physician-guided treatment in efficacy and safety parameters. Nurses' sense of competence was positively influenced.

In the present study half of participant nurses $(50.0 \%)$ has positive attitude towards toxoplasmosis infection and its prevention without significant difference between all topics $(\mathrm{P}>0.05)$. Maximal positive scores reported for "Vaccinations for communicable diseases" and "Toxoplasmosis training programs" $(55.0 \%$ each), while minimal were for "Investigations for at risk" and "Dealing with suspected cases" (42.5\% each) as illustrated.

The high score for the item of "Vaccinations for communicable diseases " may be due to the belief of the nurses that vaccination is the most effective way of preventing most of infectious diseases, and for item of "Toxoplasmosis training programs" may reflect lack of effective training programs. Low scores for "Investigations for at risk" and "Dealing with suspected cases" may give red light for a need for application of strict control measures for at risk and suspected cases. Jacobson et al. (1986) modified the CDC's guideline for disease-specific isolation precautions to a hospital computerized information system to better and more accurate use of isolation, probably due to inservice education and surveillance efforts. Wood and Gray (2000) stated that there had not been a "gold standard" identified for measuring compliance, therefore it was difficult to compare results due to differences in operational definitions. Nurses and other health care providers could promote medication compliance by developing a collaborative relationship with the patient. $\mathrm{Du}$ and $\mathrm{Hu}$ (2014) found that the intervention on Alzheimer's disease (AD) knowledge and health promotion was effective for elders in this study. Nurses should therefore provide education for elders in nursing homes to improve their $\mathrm{AD}$ knowledge and healthpromotion lifestyles, and to prevent or ameliorate AD. Ebrahimi et al. (2014) stated that with regard to the importance of time management and its vital role in the quality of nursing care for clients, and also the fact that head nurses believed more in their time management behaviors, they were expected to improve organization's goals and developments in order to modify the weaknesses and shortages and promote the skills and capabilities of their staffs and also resolve the disagreement on the understanding of time management. Moreover, effective time management training programs can be an important step for staff nurses and their head nurses.

The infection control is now in focus of most of quality improvement programs in hospitals due to wide spread and cost of nosocomial infections. Women of childbearing age and immuno-compromised patients, especially those with HIV infection, should be counseled to avoid these two risk factors (Lopes et al, 2012). Infection control or reduction of $T$. gondii in meat, improvements in hygiene and food preparation practices, 
and reduction of environmental contamination can prevent toxoplasmosis, but more research is needed on how to implement these measures. Besides, screening and treatment may help prevent toxoplasmosis or reduce the severity of disease in some settings (Jones et al, 2014)

The present study showed that $60 \%$ of participant nurses have positive compliance scale to infection control measures with significant higher score for precautions for BBPs prevention $(\mathrm{P}<0.05)$. Adequate performance for precautions for BBPs prevention may be due to available tools for its application and frequent training programs for infection control measures and sharps' safety.

As regard years of experience, Polaschek (2007) reported that understanding client attitudes towards therapy enables nurses to support people living on dialysis better. Through enhancing their relationships with clients, nurses can assume a key role in service to people living with chronic conditions.

As regards the relationship between the nurses' socidemographic data and total knowledge' attitude and compliance to infection control measures score showed significant difference between the total mean knowledge \% score according to gender, education, and marital status ( $\mathrm{P}>0.05)$. Also, there was a statistically significant difference between the total mean attitude \% score according to gender, education, and marital status $(\mathrm{P}<0.05)$. However, there was a significant difference between the total mean compliance $\%$ score according to education and years of experience $(\mathrm{P}<0.05)$, but without significant differences in all other items. Trinkoff et al (2006) reported that the proportion of nurses who reported working schedules that exceed the recommendations of the Institute of Medicine should raise industry-wide concerns about fatigue and health risks to nurses as well as the safety of patients in their care. Alabaster (2007) reformed nurse education, service modernisa- tion and changing roles have modified traditional views of nursing older people but not overturned them. Nurses in age-specific and non-acute areas were more likely to practise and encourage a person-centred approach, this being consistent with students' ideals. Decker et al. (2008) reported that successful change in clinical processes and organizational culture can be accomplished through multidisciplinary collaboration. A randomized trial of PREDICT consent, leveraging the accumulated knowledge from this first experience, is needed to further evaluate its impact on medical decision-making, patient compliance, and clinical outcomes. Zabalegui and Cabrera (2009) stated that nursing education in Spain is developing rapidly in accordance with the European Union growth and within an international globalization movement and that current nursing specialties included family and community health nursing, midwifery, mental health nursing, geriatric nursing, health work nursing, medical care nursing and pediatric nursing. They concluded that the new nursing education structure being expected to improve health care as well as nursing reliability and autonomy.

Ward (2010) found that poor practice in clinical placements can have a negative impact on student learning and practice and may therefore have implications for the practice of future nurses and midwives. In order to maintain patient safety, there needs to be more support for students who wish to identify poor practice. The present results agreed with Khudair and Raza (2013) found that highly significant relation between nurse's level of knowledge and their age. In contrast to these results found that younger ages are associated with higher satisfactory knowledge rate and they explained that by new graduation and refresh memory with advances in learning programs in nursing specialty in the last years. Liu et al. (2014) stated that nurse Care for patients with heart failure, particularly older adults, should focus on teaching these patients about heart 
failure illness and symptom management. Assisting elderly patients with heart failure to promote and maintain physical functions to handle activities of daily living independently is critical to improving patient quality of life. Shahsavari et al. (2014) stated that the clinical education is the heart of the nursing education program. They concluded that effective clinical nurse instructor evaluation tool gave acceptable psychometric properties and can be used in evaluating the effectiveness of clinical nursing instructors.

Sedgwick et al. (2014) found that every interaction that minority students have with clinical nursing instructors, registered nurses, and their student peers has the potential to impact belongingness. Engaging in reflection, developing mission statements that appreciate and value diversity, and using transformative learning strategies enhance minority students' sense of belonging.

\section{Conclusion}

Generally speaking, toxoplasmosis is a worldwide distributed disease, characterized by a complex epidemiology. The risk of infection for humans depends on their contact with infective oocysts in a contaminated environment and on the amount of tissue cysts located within consumed meat. Unfortunately, the prevalence of tissue cysts is largely unknown for game species. Cat feces and meat are the most important sources of infection. On the other hand, $T$. gondii is a serious threat particularly to female particularly pregnant, non-immune women and their babies and congenital toxoplasmosis is another risk to man and animal. Pregnant women are more severely affected by infections with some organisms, including influenza virus, hepatitis E virus, and herpes simplex virus, and malaria parasites. The evidence is more limited for organisms that cause coccidioidomycosis, measles, smallpox, and varicella. The threshold for diagnostic evaluation, as well as hospitalization and treatment, may be lower for pregnant women than for other patients, and this fac- tor may bias some of the reports of increased disease severity. As the majority of the samples were females, they showed great interest in this critically important disease. The outcome results showed that: $1-22.2 \%$ of pregnant and $20 \%$ of non-pregnant females were detected to be positive for antibodies anti-Toxoplasma gondii. 2- Almost half of participant nurses have satisfactory knowledge level as regard toxoplasmosis without significant difference between all topics. 3- There was a significant difference between the total mean knowledge \% score according to gender, education, and marital status $(\mathrm{P}>0.05)$. 4- Half of participant nurses had positive attitude towards toxoplasmosis infection and its prevention without significant difference between all topics $(\mathrm{P}>0.05)$. 5- There was a statistically significant difference between total mean attitude $\%$ score according to sex, education, and marital status $(\mathrm{P}<0.05) .6-60 \%$ of participant nurses had positive compliance regarding infection control measures with significant higher score for precautions for BBPs prevention $(\mathrm{P}<0.05)$. 7- There was a significant difference between the total mean compliance score according to education and years of experience $(\mathrm{P}<0.05)$.

\section{Recommendations}

1- Health education about toxoplasmosis should be tailored to women of childbearing age may help to prevent its complications. 2- Frequent periodic IHAT should be done for people who continuously contact with cats. 3- Adherence to strict infection prevention measures is a must to eliminate exposure to toxoplasmosis infection. 4- Hospital should put a policy of systematic procedure for recording, reporting, analyzing, investigating toxoplasmosis infection. 5- Training intervention should be implemented to achieve successful improvement in knowledge, attitude, and compliance of toxoplasmosis control measures. 6- Health system should offer education that help prevention of toxoplasmosis in females and immunosuppressed patients. 7- Livestock management and their 
meat and milk products influence the human toxoplasmosis risk. 8- More researches are ongoing to evaluate prevalence of toxoplasmosis among nurses and also to focus on specific impact of training intervention on improving their knowledge, attitude, and compliance.

\section{References}

Abbas, SA, Basalamah, A, Serebour, F, Alfonso, M, 1986: Toxoplasma gondii antibodies in Saudi women and outcome of congenital infection among new-borne in Saudi Arabia. Saudi Med. J. 7:346-54.

Abdulmawjood, A, Rosa, S, Taubert, A, Bauer, C, Failing, K, et al, 2014: Toxoplasma gondii in raw sausages using in-house developed and validated real time-PCR. Meat Sci. 97, 4: $542-7$

Abeni, MS, Magni, M, Conte, M, Mangiacavalli, S, Pochintesta, L, et al, 2014: Psychological care of caregivers, nurses and physicians: a study of a new approach. Cancer Med. 3, 1: 101-10.

Alabaster, E, 2007: Involving students in the challenges of caring for older people. Nurs. Older People 19, 6:23-8.

Al-Kappany, YM, Lappin, MR, Kwok, OC, Abu-Elwafa, SA, Hilali, M, 2011: Sero-prevalence of Toxoplasma gondii and concurrent Bartonella spp., feline immunodeficiency virus, feline leukemia virus, and Dirofilaria immitis infections in Egyptian cats. J. Parasitol. 97, 2:256-8. Al-Kappany, YM, Rajendran, C, Abu-Elwafa, SA, Hilali, M, Su, C, 2010: Genetic diversity of Toxoplasma gondii isolates in Egyptian feral cats reveals new genotypes. J. Parasitol. 96, 6:1112-4.

Alonso, R, Heiman, P, Mancall, EL, 1984: Cerebral toxoplasmosis in acquired immune deficiency syndrome. Arch. Neurol., 41:321-3.

Amin, TT, Ali, MN, Alrashid, AA, Al-Agnam, AA, Al Sultan, AA, 2013: Toxoplasmosis preventive behavior and related knowledge among Saudi pregnant women: an exploratory study. Glob. J. Hlth. Sci. 5, 5:131-43.

Bampi, LN, Baraldi, S, Guilhem, D, Pompeu, RB, Campos, AC, 2013: Nurse undergraduate students' perception of quality of life. Rev. Gaucha Enferm. 34, 2:125-32.

Barsoum, RS, 2006: Parasitic infections in transplant recipients. Nat. Clin. Pract. Nephrol. 2: 490-503.
Bazaco, MC, Albrecht, SA, Malek, AM, 2008: Preventing foodborne infection in pregnant women \& infants. Nurs. Women Hlth. 12, 1:46-55.

Behbehani, K, Al-Karmi, T, 1980: Toxoplasmosis in Kuwait: Detection of $T$. gondii antibodies and distribution \% among inhabitants. Trans. R. Soc. Trop. Med. Hyg. 74:209-12.

Chaudhry, SA, Gad, N, Koren, G, 2014: Toxoplasmosis and pregnancy. Can. Fam. Physician 60, 4:334-6.

Costa DG, Marvulo MF, Silva JS, Santana SC, Magalhães, FJ, et al, 2012: Seroprevalence of Toxoplasma gondii in domestic and wild animals from the Fernando de Noronha, Brazil. J. Parasitol. 98, 3:679-80.

Decker, C, Arnold, SV, Olabiyi, O, Ahmad, H, Gialde, E, et al, 2008: Implementing an innovative consent form: the PREDICT experience. Implement. Sci. 3:58-64.

Du, L, Hu, J, 2014: The effects of health education on knowledge about Alzheimer's disease and health-promoting behaviours of older Chinese adults in a nursing home: A pilot study. Int. J. Nurs. Pract. May 12. doi: 10.1111/ijn. 12349.

Ebrahimi. H, Hosseinzadeh, R, Tefreshi, MZ, Hosseinzadeh, S, 2014: Time management behaviors of head nurses and staff nurses employed in Tehran Social Security Hospitals, Iran in 2011. Iran J. Nurs. Midwifery Res. 19, 2:1938.

Eissa, MH, Abdel Salam, AM, Herez, HA, Younis, TA, Morsy, TA, 1990: Placental villous maturation in patients with repeated abortions and chronic toxoplasmosis. J. Egypt. Soc. Parasitol. 20, 2:661-6.

El Behairy, AM, Choudhary, S, Ferreira, LR, Kwok, OC, Hilali, M, et al, 2013:Genetic characterization of viable Toxoplasma gondii isolates from stray dogs from Giza, Egypt. Vet. Parasitol.193, 1/3:25-9

El-Jardali, F, Murray, SF, Dimassi, H, Jamal, D, Abualrub, R, et al, 2013: Intention to stay of nurses in current posts in difficult-to-staff areas of Yemen, Jordan, Lebanon and Qatar: a crosssectional study. Int. J. Nurs. Stud. 50, 11:148194.

Elsheikha, HM, Morsy, TA, 2009: Role of immune response in Toxoplasma gondii tachyzoite-bradyzoite stage interconversion: A Janus in determining disease outcome. J. Egypt. Soc. Parasitol. 39, 2:595-8.

Elsheikha, HM, El-Motayam, MH, Abouel-Nour, F, Morsy, AT, 2009: Oxidative stress and 
immune-suppression in Toxoplasma gondii positive blood donors: implications for safe blood transfusion. J. Egypt. Soc. Parasitol. 39, 2:421-8 Freimann, T, Coggon, D, Merisalu, E, Animägi, L, Pääsuke, M, 2013: Risk factors for musculoskeletal pain amongst nurses in Estonia: a cross-sectional study. BMC Musculoskelet. Disord. 2013 Dec 1;14:334.doi:10.1186/1471-247414-334.

Griffin, L, Williams KA, 1983: Serological and parasitological survey of blood donors in Kenya for toxoplasmosis. Trans. Roy. Soc. Trop. Med. Hyg. 6:143-5.

Harfoush, M, Tahoon, AN, 2010: Seroprevalence of Toxoplasma gon-dii antibodies in domestic ducks, free-range chickens, turkeys and rabbits in Kafr El-Sheikh Governorate Egypt. J. Egypt. Soc. Parasitol. 40, 2: 295-302.

Haridy, FM, Saleh, NMK, Khalil, H HM, Morsy, TA, 2010: Anti-Toxoplasma gondii antibodies in working donkeys and donkey's milk in Greater Cairo, Egypt. J. Egypt. Soc. Parasitol. 40, 2:459-64.

Haridy, FM, Shoukry, NM, Hassan, AA, Morsy, TA, 2009: ELISA-seroprevalence of Toxoplasma gondii in draught horses in Greater Cairo, Egypt. J. Egypt. Soc. Parasitol. 39, 3:821-6.

Hilali, M, Romand, S, Thulliez, P, Kwok, OC, Dubey, JP, 1998: Prevalenceof Neospora caninum andToxoplasma gondii antibodies in serumfrom camels from Egypt. Vet. Parasitol.75, 2/3: 269-71.

Hill, D, Dubey, JP, 2002: Toxoplasma gondii: transmission, diagnosis and prevention. Clin. Microbiol. Infect. 8:634-40.

Jackson, M, Hutchinson, WM, 1987: A seroepidemiological survey of toxoplasmosis in Scotland and England. Ann. Trop. Med. Parasitol. 81:55-65.

Jacobson, JT, Johnson, DS, Ross, CA, Conti, MT, Evans, RS, et al, 1986: Adapting diseasespecific isolation guidelines to a hospital information system. Infect. Control 7, 8:411-8

Jones, J, Kruzon-Moran, D, Wilson, M, 2007: Toxoplasma gondii infection in the United States. Emerg. Infect. Dis. 9, 11:137-4.

Jones, JL, Parise, ME, Fiore, AE, 2014: Neglected parasitic infections in the United States: toxoplasmosis. Am. J. Trop. Med. Hyg. 90, 5: 794-9.

Jones, JL, Roberts, JM, 2012: Toxoplasmosis hospitalizations in the United States, 2008, and trends, 1993-2008. Clin. Infect. Dis. 6, 7:e5861.

Kassem, HH, Morsy, TA, 1991: The prevalence of anti-Toxoplasma antibodies among pregnant woman in Benghazi (S.P.L.A.J.), Libya. J. Egypt. Soc. Parasitol. 21, 1:69-74.

Khalid, MLM, Morsy, TA, Sadek, MSM, Salama, MI, 1982: The presence of antibodies against toxoplasmosis, leishmaniasis and amoebiasis in stray dogs in Cairo, Egypt. J. Egypt. Soc. Parasitol. 12, 2:341-7.

Khudair, IF, Raza, SA, 2013: Measuring patients' satisfaction with pharmaceutical services at a public hospital in Qatar. Int. J. Hlth. Care Qual. Assur. 26, 5:398-419.

Lilly, EL, Wortham, CD, 2013: High prevalence of Toxoplasma gondii oocyst shedding in stray and pet cats (Felis catus) in Virginia, United States. Parasit. Vectors 2013 Sep 17;6:266. doi:10.1186/1756-3305-6-266.

Liou, SR, Cheng, CY, 2010: Organisational climate, organisational commitment and intention to leave amongst hospital nurses in Taiwan. J. Clin. Nurs. 19, 11/12:1635-44.

Liu, MH, Wang, CH, Huang, YY, Cherng, W J, Wang, KW, 2014: A correlational study of illness knowledge, self-care behaviors, and quality of life in elderly patients with heart failure. J. Nurs. Res. 22, 2:136-45

Lopes, AP, Dubey, JP, Moutinho, O, Gargaté, MJ, Vilares, A, et al, 2012: Sero-epidemiology of Toxoplasma gondii infection in women from the North of Portugal in their childbearing years. Epidemiol. Infect. 140:872-7.

Moncada, PA, Montoya, JG, 2012: Toxoplasmosis in the fetus and newborn: an update on prevalence, diagnosis and treatment. Expert Rev. Anti. Infect. Ther. 10, 7:815-28.

Morsy, TA, Michael, SA, 1980: Toxoplasmosis in Jordan. J. Egypt. Soc. Parasitol. 10, 2:457-70.

Morsy, TA, Shoukry, A, Abu-Hashish, TA, El Kady, GA, 1987: Toxoplasma antibodies in commensal rodents in El Arish City, Egypt. J. Egypt. Soc. Parasitol. 17, 2:799-801.

Mumcuoglu, I, Toyran, A, Cetin, F, Coskun, FA, Baran, I, et al, 2014: Evaluation of the toxoplasmosis seroprevalence in pregnant women and creating a diagnostic algorithm. Mikrobiyol. Bul. 48, 2:283-91

Mutale, W, Ayles, H, Bond, V, Mwanamwenge, MT, Balabanova, D, 2013a: Measuring health workers' motivation in rural health facilities: 
baseline results from three study districts in Zambia. Hum. Resour. Hlth. Feb 21;11(1):8. doi: 10.1186/1478-4491-11-8.

Mutale, W, Mwanamwenge, MT, Balabanova, D, Spicer, N, Ayles, H, 2013b: Measuring governance at health facility level: developing and validation of simple governance tool in $\mathrm{Za}$ mbia. BMC Int. Hlth. Hum/Rights. Aug 9; 13: 34. doi: 10.1186/1472-698X-13-34

Onadeko, MO, Joynson, DH, Payone, RA, 1992: The prevalence of Toxoplasma infection among pregnant women in Ibadan, Nigeria. J. Trop. Med. Hyg. 95:143-5.

Pappas, G, Roussos, N, Falagas, ME, 2009: Toxoplasmosis snapshots: Global status of Toxoplasma gondii sero-prevalence and implications for pregnancy and congenital toxopla-smosis. Int. J. Parasitol. 39, 12:1385-94.

Polaschek, N, 2007: Doing dialysis at home: Client attitudes towards renal therapy. J. Clin. Nurs. 16, 3A:51-8.

Rifaat, MA, Morsy, TA, Sadek, MSM, 1969: Toxoplasmosis in chickens and pigeons in U.A.R. (Preliminary report). J. Trop. Med. Hyg. 72:193-4.

Rifaat, MA, Morsy, TA, Sadek, MSM, Khalid, ML, Azab, ME, 1977: Incidence of toxoplasmosis among farm animals in Suez Canal Governorates. J. Egypt. Soc. Parasitol. 7, 2:135-40.

Sedgwick, M, Oosterbroek, T, Ponomar, V, 2014: "It all depends": how minority nursing students experience belonging during clinical experiences. Nurs. Educ. Perspect. 35, 2:89-93.

Segal, G, Karniel, E, Mahagna, A, Kaa'dan, F, Levi, Z, et al, 2014: A nurse-guided, basalprandial insulin treatment protocol for achieving glycaemic control of hospitalized, non-critically ill diabetes patients, is non-inferior to physicianguided therapy: A pivotal, nurse-empowerment study. Int. J. Nurs. Pract. Apr 1. doi: 10. 1111/ ijn.12292.

Serebour, F, Alfonso, M, 1986: Toxoplasma gondii antibodies in Saudi women and outcome of congenital infection among new-borne in Saudi Arabia. Saudi Med. J. 7:346-54.

Shahsavari, H, Yekta, ZP, Zare, Z, Sigaroodi, AE, 2014: Iranian Effective Clinical Nurse Instructor evaluation tool: Development and psychometric testing. Iran J. Nurs. Midwifery Res. 19, 2:132-8.

Shoura, MA, Morsy, TA, El Dasouqui, IT, 1973: Toxoplasmin skin tests in Riyadh, Saudi
Arabia. J. Trop. Med. Hyg. 76, 10: 254.

Silva, MS, da Silva, IS, Abate, G, Masini, JC, 2001: Spectrophotometric determination of acid volatile sulfide in river sediments by sequential injection analysis exploiting the methylene blue reaction. Talanta. 53, 4:843-50.

Stagno, S, 1980: Congenital toxoplasmosis. Am. J. Dis. Child. 134: 635-7.

Su, C, Khan, A, Zhou, P, Majumdar, D, Ajzenberg, D, et al, 2012: Globally diverse Toxoplasma gondii isolates comprise six major clades originating from a small number of distinct ancestral lineages. Proc. Natl. Acad. Sci. USA. 7, 15:5844-9.

Sudan, V, Jaiswal AK, Shanker, D, 2013: Recent trends in the diagnosis of toxoplasmosis. Clin. Rev. Opinions 5, 2:11-7.

Tabi, MM, Doster, C, Cheney, T, 2010: A qualitative study of women in polygynous marriages. Int. Nurs. Rev. 57, 1:121-7.

Trinkoff, A, Geiger-Brown, J, Brady, B, Lipscomb, J, Muntaner, C, 2006: How long and how much are nurses now working? Am. J. Nurs. 106, 4:60-71.

Wallon, M, Peyron, F, Cornu, C, Vinault, S, Abrahamowicz, M, et al, 2013: Congenital Toxoplasma infection: monthly prenatal screening decreases transmission rate and improves clinical outcome at age 3 years. Clin. Infect. Dis. 56, 9:1223-31.

Ward, DJ, 2010: Infection control in clinical placements: experiences of nursing and midwifery students. J. Adv. Nurs. 66, 7:1533-42.

Wishahy, AO, Rifaat, MA, Morsy, TA, ElNaggar, BA, 1973: Toxoplasmosis in children with some neurological manifestations. J. Trop. Med. Hyg. 75, 12:255-6.

Wood, W, Gray, J, 2000: An integrative review of patient medication compliance from 19901998. Online J. Knowl. Synth. Nurs. 14, 7:1-8.

Yang, Y, Zhao, RY, Lan, MJ, 2008: Effect of sleep quality on day cycle fatigue in ward nurses. Zhonghua Lao Dong Wei Sheng Zhi Ye Bing Za Zhi. 26, 6:360-2.

Zabalegui, A, Cabrera, E, 2009: New nursing education structure in Spain. Nurse Educ. Today 29, 5:500-4.

Ziemba, J, Nowakowska, A, Wilczyński, J, Maniecka, BI, Nowakowska, D, 2010: Knowledge of toxoplasmosis among pregnant women, midwifes, medical students and obstetricians.

Med. Pract. 61, 3:271-6. 